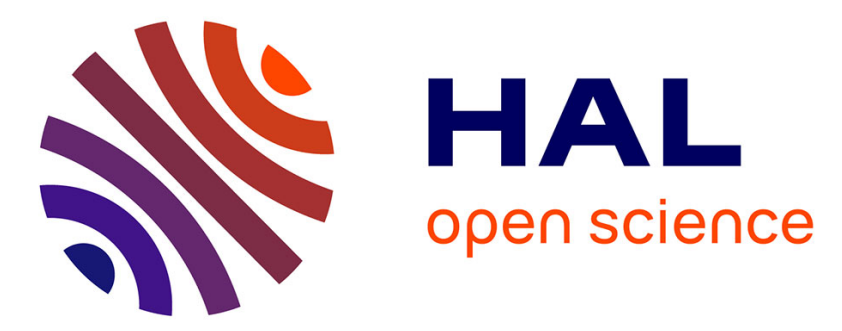

\title{
Redox-controlled hybridization of helical foldamers
}

Lara Faour, Catherine Adam, Christelle Gautier, Sébastien Goeb, Magali

Allain, Eric Levillain, David Canevet, Marc Sallé

\section{To cite this version:}

Lara Faour, Catherine Adam, Christelle Gautier, Sébastien Goeb, Magali Allain, et al.. Redoxcontrolled hybridization of helical foldamers. Chemical Communications, 2019, 55 (40), pp.5743-5746. 10.1039/C9CC02498K . hal-02322934

\section{HAL Id: hal-02322934 \\ https://hal.science/hal-02322934}

Submitted on 4 Jun 2020

HAL is a multi-disciplinary open access archive for the deposit and dissemination of scientific research documents, whether they are published or not. The documents may come from teaching and research institutions in France or abroad, or from public or private research centers.
L'archive ouverte pluridisciplinaire HAL, est destinée au dépôt et à la diffusion de documents scientifiques de niveau recherche, publiés ou non, émanant des établissements d'enseignement et de recherche français ou étrangers, des laboratoires publics ou privés. 


\section{Redox-controlled hybridization of helical foldamers}

Received 00th January 20xx

Lara Faour, Catherine Adam, Christelle Gautier, Sébastien Goeb, Magali Allain, Eric Levillain, David Canevet, ${ }^{*}$ Marc Sallé *

Accepted 00th January 20xx

DOI: $10.1039 / \times 0 \times x 00000 x$

Tetrathiafulvalene redox units were grafted at both extremities of an oligopyridine-dicarboxamide foldamer through a straightforward copper-catalyzed azide-alkyne cycloaddition. The present work demonstrates that the hybridization equilibrium of foldamers can be tuned through redox stimulations.

Foldamers ${ }^{[1,2]}$ constitute a family of synthetic oligomers that adopt well-defined secondary structures and have focused a growing attention over the last years, ${ }^{[3-7]}$ notably to understand and mimic biological functions. Outstanding achievements have been reported in various research fields, such as pharmacology, catalysis, or host-guest chemistry. ${ }^{[7-10]}$ Much efforts have also been devoted to the formation of discrete supramolecular structures, such as double, triple or even quadruple helices, ${ }^{[11]}$ since helical single strands actively participate in biological processes (e.g. ribonucleic acids) and can form hybridized structures (i.e. multiple helices).

The parameters governing the latter equilibria are intrinsically associated to solute-solute and solute-solvent interactions. In particular, it was proven possible to shift the equilibrium towards the hybridized structures by increasing the concentration, lowering the temperature ${ }^{[12,13]}$ or taking advantage of solvophobic effects. ${ }^{[14,15]}$ Moreover, the presence of a cavity inside the loops of miscellaneous foldameric backbones has also encouraged the community to evaluate the impact of guest binding over this supramolecular process. ${ }^{[16,17]}$ While it is sometimes possible to shift the equilibrium by controlling the temperature in a reversible manner, reversibility is hardly reached when diluting a solution, changing the solvent or introducing a guest, due to experimental issues. Therefore, controlling in a reversible way the equilibrium between single

\footnotetext{
a. Laboratoire MOLTECH-Anjou, UMR CNRS 6200, UNIV Angers, SFR MATRIX, 2 Bd Lavoisier, 49045 Angers Cedex, France.

david.canevet@univ-angers.fr, marc.salle@univ-angers.fr

Electronic Supplementary Information (ESI) available: Experimental details, ${ }^{1} \mathrm{H}$

and ${ }^{13} \mathrm{C}$ NMR spectra, mass spectrometry information, crystallographic structure, cyclic voltammetry and additional spectroelectrochemistry experiments. CCDC 1891841. For ESI and crystallographic data in CIF or other electronic format, see DOI: $10.1039 / x 0 \times x 00000 x$
}

and hybridized helices constitutes an exciting challenge to tackle. Such a breakthrough requires identifying a stimulus, which does not affect the composition of the medium upon converting the single helix to the corresponding hybridized structure, notably when the process is performed several times. In this context, a proof-of-principle has been recently reported with photochemical stimulations by Flood and coworkers. ${ }^{[18]}$ On the other hand, redox chemistry appears particularly relevant to promote attractive/repulsive interactions between electroactive subunits, without displaying the drawbacks associated to photochemical inputs and associated thermal relaxation processes. In particular, the radical-cation dimerization phenomenon ( $\pi$-dimerization) has recently emerged as a valuable new type of interaction of the supramolecular toolbox. ${ }^{[19,20]}$ Such reversible non-covalent bonds have been reported from different redox units, such as viologen (upon reduction of $\left.\mathrm{V}^{2+}\right)^{[21]}$ or tetrathiafulvalene (upon oxidation of TTF). ${ }^{[22-28]}$ Herein, the latter system ${ }^{[29]}$ was selected for multiple reasons: 1 ) it can be reversibly and successively oxidized into the radical cation $\mathrm{TTF}^{+} \cdot$ and the aromatic dication $\mathrm{TTF}^{2+}$ states, even under aerobic conditions, 2) these redox reactions can be carried out either chemically or electrochemically, with a full control over the oxidized species that are produced, 3) the corresponding radical cation dimers display clear spectroscopic signatures, though only observable under certain specific conditions. ${ }^{[30]}$ Consequently, TTF units were covalently grafted at both extremities of an oligopyridinedicarboxamide backbone ${ }^{[5,31]}$ endowed with five pyridyl rings. The latter skeleton was selected for its ability to hybridize with a moderate dimerization constant, ${ }^{[2,33]}$ its transparency in the visible range, and its redox inactivity in a wide range of potentials. ${ }^{[34]}$ From the resulting compound $\mathbf{3}$ (Scheme 1), we demonstrate herein an unprecedented control over the dimerization equilibrium of a foldamer through redox stimulation.

The synthesis of target foldamer $\mathbf{3}$ is depicted in Schemes 1 and S1. The key step involves a copper-catalyzed azide-alkyne cycloaddition (CUAAC) ${ }^{[35-37]}$ between the unreported bis(alkyne) 

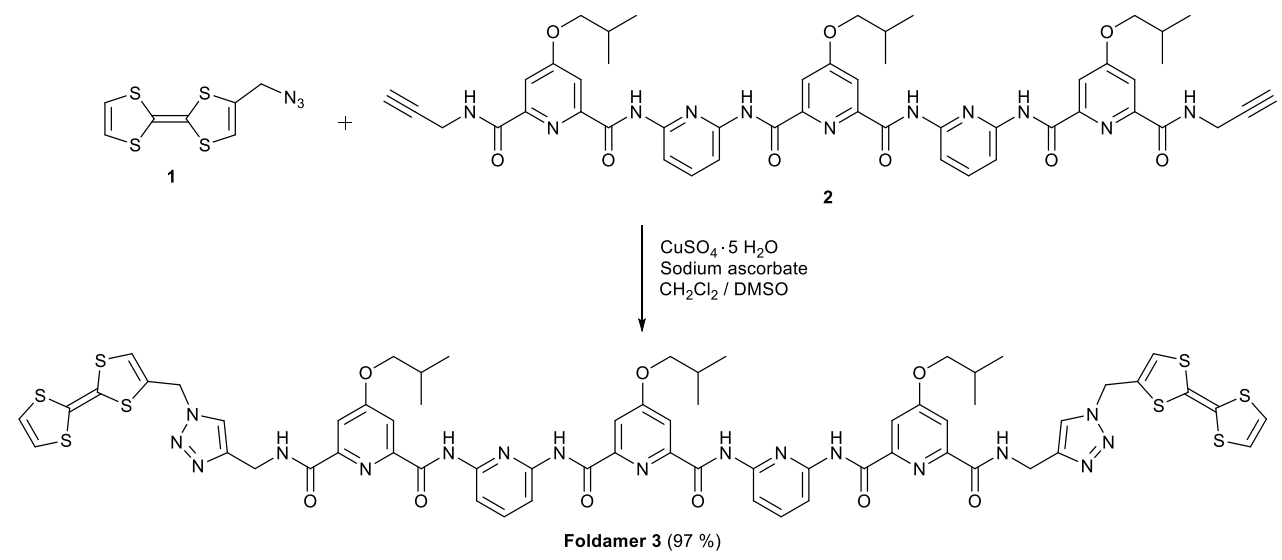

Scheme 1. Synthesis of electroactive foldamer 3.

functionalized foldamer $\mathbf{2}$ and azidomethyltetrathiafulvalene $1{ }^{138]}$ in the presence of copper (II) sulfate pentahydrate and sodium ascorbate (See supporting information for synthetic details). One will note the high synthetic potential offered by key intermediate 2, which allows to envisage the grafting of various types of azide derivatives and hence, a straightforward access to functionalized foldamers. Target compound $\mathbf{3}$ was isolated with a $97 \%$ yield (Scheme 1) and its structure was unequivocally confirmed, notably through the resolution of a crystallographic structure (Figure 1). The corresponding crystals were grown by slow diffusion of methanol onto a dichloromethane solution of foldamer 3 . Under these conditions, the latter adopts a single helical structure in the solid state and displays the expected intramolecular hydrogen bonds (See Figure S1). ${ }^{[12]}$ Our efforts to grow single crystals of the hybridized foldamer, i.e. adopting a double helical arrangement, proved unsuccessful, which most likely results from a weak equilibrium constant. This was confirmed by performing variable-concentration $\mathrm{NMR}$ experiments in deuterated chloroform (Figure S2) and in a $\mathrm{CD}_{2} \mathrm{Cl}_{2} / \mathrm{CD}_{3} \mathrm{CN}(1 / 1$ $(v / v)$ ) mixture at $273 \mathrm{~K}$ (Figure S3). At this temperature, the equilibrium was slow on the NMR timescale, which allowed a straightforward determination of the dimerization constant $\mathrm{K}_{\text {dim }}\left(\mathrm{CDCl}_{3}\right)=25 \pm 9$ and $\mathrm{K}_{\operatorname{dim}}\left(\mathrm{CD}_{2} \mathrm{Cl}_{2} / \mathrm{CD}_{3} \mathrm{CN}\right)=5.2( \pm 0.8) \times 10^{2}$ (See supporting information file). One will also note that mass spectrometry (FTICR) measurements (Figure S4) showed the presence of both the monomer and the dimer species, but no
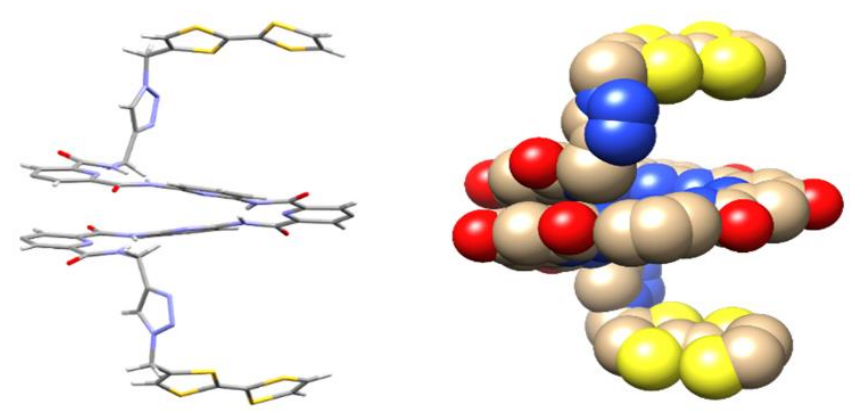

Figure 1. Crystallographic structure of foldamer 3. Solvent molecules and isobutoxy chains omitted for clarity. larger aggregates. In view to explore the impact of radicalcation dimerization over the supramolecular behaviour of foldamer 3, chemical oxidations were led by titration with thianthrenium tetrafluoroborate $\left(\mathrm{ThBF}_{4}\right)$ (Figure S5). ${ }^{[39]}$ These experiments were performed in a mixture of dichloromethane and acetonitrile $(1 / 1 v / v)$, to ensure solubility for both the foldamer and the thianthrenium salt, and followed by UV-visible absorption spectroscopy. Upon addition of the oxidizing agent, typical absorption bands for radical cation $\mathrm{TTF}^{+}$appeared at 437 and $585 \mathrm{~nm}$. Concomitantly, a broad band centred at 770 $\mathrm{nm}$ indicated the formation of radical-cation dimers $\left(\mathrm{TTF}^{+\bullet}\right)_{2} \cdot{ }^{[40]}$ At this stage, it is worth noting that the formation of the $\pi$ $\left(\mathrm{TTF}^{+\bullet}\right)_{2}$ dimer at room temperature has been observed only in very specific cases, e.g. either through confinement of two TTF units within a cavity, ${ }^{[41,42]}$ with covalently preorganized TTF units, ${ }^{[40,43-45]}$ or with interlocked structures. ${ }^{[23]}$ Therefore, this observation in the case of foldamer 3 constitutes a first noticeable evidence for the spatial proximity of $\mathrm{TTF}^{+\bullet}$ units and highlights the stability of the radical-cation dimers. Finally, one will note this absorption band disappears upon further addition of oxidant, i.e. upon generation of the dicationic state $\left(\mathrm{TTF}^{2+}\right)$. With this in mind, we performed variable-concentration experiments to assess the intra or intermolecular nature of this $\pi$-dimerization process. Given the possible interactions between the foldamer and the by-products obtained when using $\mathrm{ThBF}_{4}$ (i.e. thianthrene oxide and thianthrene), spectroelectrochemical measurements appeared particularly relevant for this study. ${ }^{[46]}$ The experiments were led in the same solvent mixture as above and the evolution of the absorbance was monitored for various concentrations of foldamer $\mathbf{3}$, at a potential ensuring the $\mathrm{TTF}^{+}$radical cation state $(\mathrm{E}=0.3 \mathrm{~V}$ vs $\left.\mathrm{Ag} / \mathrm{AgNO}_{3}\right)_{.}{ }^{[47]}$ Thereby, the spectroelectrochemical setup afforded the difference $\Delta \mathrm{A}$ between the absorption spectra before and upon electrolysis. Consistently with chemical oxidation experiments, radical-cation dimerization $(\lambda=770 \mathrm{~nm})$ was very clearly observed for a foldamer concentration of $500 \mu \mathrm{M}$ (Figures 2a and S7). Moreover, it is worth noting that the occurrence of this $\left(\mathrm{TTF}^{+\bullet}\right)_{2}$ interaction appears intimately linked to the concentration, as shown by the evolution of $\Delta A_{770}$ 
a)

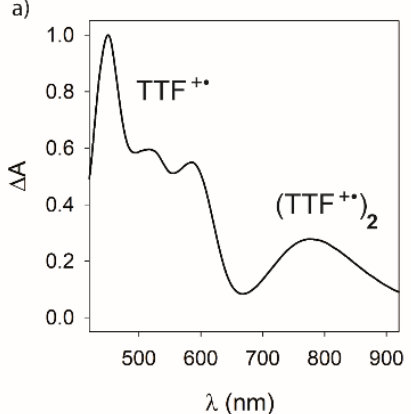

b)

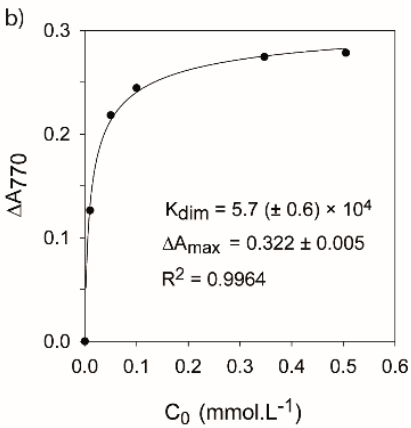

Figure 2. a) Typical normalised spectrum obtained through spectroelectrochemical measurement upon oxidation of $\mathbf{3}\left(\mathrm{C}=500 \mu \mathrm{M}, \mathrm{E}=0.3 \mathrm{~V}\right.$ vs $\mathrm{Ag} / \mathrm{AgNO}_{3}$, $\left.\operatorname{TBAPF}_{6}(0.1 \mathrm{M}), \mathrm{CH}_{2} \mathrm{Cl}_{2} / \mathrm{CH}_{3} \mathrm{CN} 1 / 1(\mathrm{v} / \mathrm{v})\right)$. b) Evolution of $\Delta \mathrm{A}_{770}$ upon oxidation of 3 (normalized UV-visible-NIR absorption spectra) as a function of foldamer concentration, $\mathrm{E}=0.3 \mathrm{~V}$ vs $\left.\mathrm{Ag} / \mathrm{AgNO}_{3}\right)$, $\operatorname{TBAPF}_{6}(0.1 \mathrm{M}), \mathrm{CH}_{2} \mathrm{Cl}_{2} / \mathrm{CH}_{3} \mathrm{CN} 1 / 1(\mathrm{v} / \mathrm{v}), \mathrm{T}$ $=293 \mathrm{~K}$

as a function of [3] when oxidized at $0.3 \mathrm{~V} v \mathrm{sg} / \mathrm{AgNO}_{3}$ (Figures $2 \mathrm{~b}$ and S7). Importantly, the nonlinear character of the corresponding relationship demonstrates the intermolecular nature of the radical cation dimerization process. On this ground, various supramolecular arrangements can be envisaged (Figure $3 a$ ): once oxidized, foldamer $3^{2(+\bullet)}$ may indeed form supramolecular polymers, macrocycles or double helical structures. To get insight into the assemblies made from foldamer 3, additional spectroelectrochemical measurements were led under the same conditions, with reference compound 4 (Figure 3b). The latter structure corresponds to both extremities of the foldamer strand $\mathbf{3}$ and is structurally unable to hybridize. These studies showed that while the spectroscopic signature of the $\pi$-dimerization $(770 \mathrm{~nm})$ was observable at concentrations as low as $10^{-5} \mathrm{~mol}^{-1} \mathrm{~L}^{-1}$ for foldamer 3 , it was only detectable at concentrations 250 times higher with reference 4 (Figure S8). Such observation excludes the growth of a supramolecular polymer upon oxidation of foldamer 3. Instead the quantitative analysis of the spectroelectrochemical data (Figure 2b) well fits with a dimerization equilibrium. Noteworthily, the corresponding calculated dimerization constant (see SI for details) $\mathrm{K}_{\mathrm{dim}}=5.7( \pm 0.6) \times 10^{4}$, proved to be two orders of magnitude larger than for the neutral foldamer 3

a)

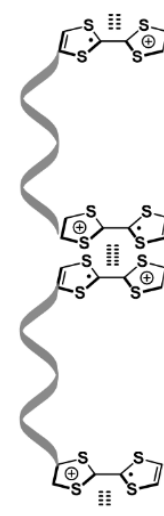

Supramolecular polymer
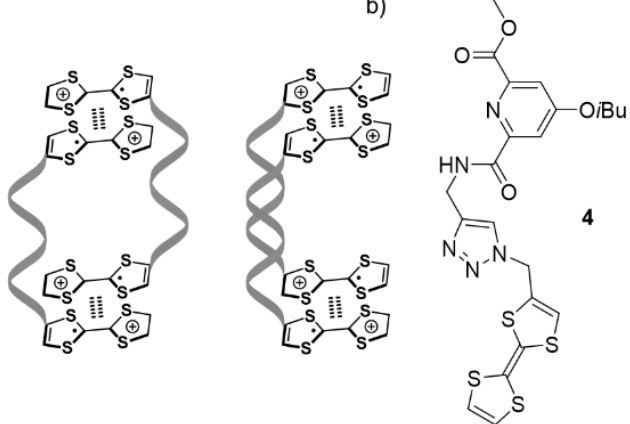

Figure 3. a) Possible supramolecular arrangements accounting for intermolecula radical-cation dimerization. b) Chemical structure of reference compound 4 .
$\left(K_{\operatorname{dim}}=5.2( \pm 0.8) \times 10^{2}\right)$ in the same solvent. These values illustrate a much stronger dimerization tendency in the case of the oxidized foldamer compared to neutral $\mathbf{3}$ and exclude the construction of a supramolecular macrocyclic structure (Figure 3 and 59). Indeed, such macrocyclic systems are only maintained through $\pi$-dimer interactions and are therefore unable to reach such high $\mathrm{K}_{\mathrm{dim}}$ values. This was evidenced for instance with a previously reported preorganized bis-TTF derivative, displaying a dimerization constant of $5.9 \times 10^{2}$ when oxidized in the same solvent mixture. ${ }^{18}$ The present experimental observation made from $\mathbf{3}$ is therefore assigned to the known propensity of oligopyridine-dicarboxamide backbones to hybridize. In this case, this behavior is remarkably reinforced by a favourable synergetic contribution of the radical cation dimerization process (Figure 3 and S9).

Controlling the hybridization equilibrium of helical foldamers constitutes an exciting challenge to tackle. With this objective in mind, we described herein the synthesis of a versatile bisalkyne foldamer, which allowed grafting tetrathiafulvalene redox units in an efficient manner. On this ground, we successfully showed that the dimerization of radical cations constitutes a relevant driving force to get control over the hybridization equilibrium $\left(\mathrm{K}_{\operatorname{dim}}\left(3^{2(\cdot+)}\right)=10^{2} \cdot \mathrm{K}_{\operatorname{dim}}(3)\right)$. These unprecedented results open promising perspectives, be that in the context of redox-controlled encapsulation or to develop smart foldamer-based materials.

\section{Conflicts of interest}

There are no conflicts to declare.

\section{Acknowledgements}

The authors are thankful to the MATRIX platform and the TGE FT-ICR (Prof. Frédéric Aubriet and Dr Vincent Carré, CNRS-Univ. Lorraine) for their assistance in NMR and mass spectrometry measurements. They also acknowledge Dr Joël Lyskawa for his kind advice regarding the synthesis of azidomethyltetrathiafulvalene. LF thanks the University of Angers for a PhD fellowship and DC is grateful to the Centre National de la Recherche Scientifique (Section 12) for a Délégation research leave.

\section{Notes and references}

[1] D. J. Hill, M. J. Mio, R. B. Prince, T. S. Hughes, J. S. Moore, Chem. Rev. 2001, 101, 3893-4012.

[2] S. Hecht, I. Huc, Eds. , Foldamers, Wiley-VCH, Weinheim, 2007.

[3] G. Guichard, I. Huc, Chem. Commun. 2011, 47, 5933-5941.

[4] E. Yashima, N. Ousaka, D. Taura, K. Shimomura, T. Ikai, K. Maeda, Chem. Rev. 2016, 116, 13752-13990.

[5] D.-W. Zhang, X. Zhao, J.-L. Hou, Z.-T. Li, Chem. Rev. 2012, $112,5271-5316$

[6] H. Juwarker, K.-S. Jeong, Chem. Soc. Rev. 2010, 39, 36643674. 
[7] H. Juwarker, J. Suk, K.-S. Jeong, Chem. Soc. Rev. 2009, 38, 3316-3325.

[8] O. M. Stephens, S. Kim, B. D. Welch, M. E. Hodsdon, M. S. Kay, A. Schepartz, J. Am. Chem. Soc. 2005, 127, 1312613127.

[9] R. A. Smaldone, J. S. Moore, Chem. - Eur. J. 2008, 14, 26502657.

[10] D.-W. Zhang, X. Zhao, Z.-T. Li, Acc. Chem. Res. 2014, 47, 1961-1970.

[11] D. Haldar, C. Schmuck, Chem. Soc. Rev. 2009, 38, 363-371.

[12] V. Berl, I. Huc, R. G. Khoury, M. J. Krische, J.-M. Lehn, Nature 2000, 407, 720-723.

[13] Y. Liu, F. C. Parks, W. Zhao, A. H. Flood, J. Am. Chem. Soc. 2018, 140, 15477-15486.

[14] J. Shang, Q. Gan, S. J. Dawson, F. Rosu, H. Jiang, Y. Ferrand, I. Huc, Org. Lett. 2014, 16, 4992-4995.

[15] J. C. Nelson, Science 1997, 277, 1793-1796.

[16] Q. Gan, Y. Ferrand, C. Bao, B. Kauffmann, A. Grelard, H. Jiang, I. Huc, Science 2011, 331, 1172-1175.

[17] Y. Hua, Y. Liu, C.-H. Chen, A. H. Flood, J. Am. Chem. Soc. 2013, 135, 14401-14412.

[18] F. C. Parks, Y. Liu, S. Debnath, S. R. Stutsman, K. Raghavachari, A. H. Flood, J. Am. Chem. Soc. 2018, 140, 17711-17723.

[19] Y. Wang, M. Frasconi, J. F. Stoddart, ACS Cent. Sci. 2017, 3, 927-935.

[20] D.-W. Zhang, J. Tian, L. Chen, L. Zhang, Z.-T. Li, Chem. - Asian J. 2015, 10, 56-68.

[21] M. Berville, L. Karmazin, J. A. Wytko, J. Weiss, Chem. Commun. 2015, 51, 15772-15775.

[22] W.-K. Wang, Y.-Y. Chen, H. Wang, D.-W. Zhang, Y. Liu, Z.-T. Li, Chem. - Asian J. 2014, 9, 1039-1044.

[23] J. M. Spruell, A. Coskun, D. C. Friedman, R. S. Forgan, A. A. Sarjeant, A. Trabolsi, A. C. Fahrenbach, G. Barin, W. F. Paxton, S. K. Dey, et al., Nat. Chem. 2010, 2, 870-879.

[24] S. V. Rosokha, J. K. Kochi, J. Am. Chem. Soc. 2007, 129, 828838.

[25] M. Fumanal, M. Capdevila-Cortada, J. S. Miller, J. J. Novoa, J. Am. Chem. Soc. 2013, 135, 13814-13826.

[26] M. Capdevila-Cortada, J. S. Miller, J. J. Novoa, Chem. - Eur. J. 2014, 20, 7784-7795.

[27] M. Fumanal, M. Capdevila-Cortada, J. J. Novoa, Phys. Chem. Chem. Phys. 2017, 19, 3807-3819.

[28] A. Trabolsi, N. Khashab, A. C. Fahrenbach, D. C. Friedman, M. T. Colvin, K. K. Cotí, D. Benítez, E. Tkatchouk, J.-C. Olsen, M. E. Belowich, et al., Nat. Chem. 2010, 2, 42-49.

[29] D. Canevet, M. Sallé, G. Zhang, D. Zhang, D. Zhu, Chem. Commun. 2009, 2245-2269.

[30] V. Khodorkovsky, L. Shapiro, P. Krief, A. Shames, G. Mabon, A. Gorgues, M. Giffard, Chem. Commun. 2001, 2736-2737.

[31] I. Huc, Eur. J. Org. Chem. 2004, 17-29.

[32] B. Baptiste, J. Zhu, D. Haldar, B. Kauffmann, J.-M. Léger, I. Huc, Chem. - Asian J. 2010, 5, 1364-1375.

[33] H. Jiang, V. Maurizot, I. Huc, Tetrahedron 2004, 60, 1002910038.

[34] F. Aparicio, L. Faour, M. Allain, D. Canevet, M. Sallé, Chem. Commun. 2017, 53, 12028-12031.

[35] C. W. Tornøe, C. Christensen, M. Meldal, J. Org. Chem. 2002, 67, 3057-3064.

[36] V. V. Rostovtsev, L. G. Green, V. V. Fokin, K. B. Sharpless, Angew. Chem. Int. Ed. 2002, 41, 2596-2599.

[37] L. Liang, D. Astruc, Coord. Chem. Rev. 2011, 255, 2933-2945.
[38] I. Kaminska, A. Barras, Y. Coffinier, W. Lisowski, S. Roy, J. Niedziolka-Jonsson, P. Woisel, J. Lyskawa, M. Opallo, A. Siriwardena, et al., ACS Appl. Mater. Interfaces 2012, 4, 5386-5393.

[39] G. Szalóki, V. Croué, V. Carré, F. Aubriet, O. Alévêque, E. Levillain, M. Allain, J. Aragó, E. Ortí, S. Goeb, et al., Angew. Chem. Int. Ed. 2017, 56, 16272-16276.

[40] J. Lyskawa, M. Sallé, J. Y. Balandier, F. Le Derf, E. Levillain, M. Allain, P. Viel, S. Palacin, Chem. Commun. 2006, 2233-2235.

[41] A. Y. Ziganshina, Y. H. Ko, W. S. Jeon, K. Kim, Chem. Commun. 2004, 10, 806-807.

[42] M. Yoshizawa, K. Kumazawa, M. Fujita, J. Am. Chem. Soc. 2005, 127, 13456-13457.

[43] M. Hasegawa, K. Daigoku, K. Hashimoto, H. Nishikawa, M. Iyoda, Bull. Chem. Soc. Jpn. 2012, 85, 51-60.

[44] C. A. Christensen, L. M. Goldenberg, M. R. Bryce, J. Becher, Chem. Commun. 1998, 509-510.

[45] C. Bejger, C. M. Davis, J. S. Park, V. M. Lynch, J. B. Love, J. L. Sessler, Org. Lett. 2011, 13, 4902-4905.

[46] N.d.

[47] J. Lyskawa, D. Canevet, M. Allain, M. Sallé, Tetrahedron Lett. 2010, 51, 5868-5872. 